\title{
Toxic Sensorium
}

\section{Agrochemicals in the African Anthropocene}

\author{
Serena Stein and Jessie Luna
}

\begin{abstract}
Pesticides and toxicity are constitutive features of modernization in Africa, despite ongoing portrayals of the continent as "too poor to pollute." This article examines social science scholarship on agricultural pesticide expansion in Sub-Saharan Africa. We recount the rise of agrochemical usage in colonial projects that placed African smallholder farmers at the forefront of toxic vulnerability. We then outline prevalent literature on "knowledge deficits" and unsafe farmer practices as approaches that can downplay deeper structures. Missing in this literature, we argue, are the embodied and sensory experiences of African farmers as they become pesticide users, even amid an awareness of toxicity. Drawing on ethnographic research in Mozambique and Burkina Faso, we explore how the "toxic sensorium" of using agrochemicals intersects with farmers' projects of modern aspiration. This approach can help elucidate why and how differently situated farmers live with pesticides, thereby expanding existing literature on structural violence and knowledge gaps.
\end{abstract}

KEYWORDS: Africa, agriculture, embodiment, pesticides, sensorium, toxicity

Toxic exposure in Africa has been largely invisible to the Global North, overshadowed by dominant perceptions of Africa as mired in a preindustrial past rather than living with the contaminations of modernity. This portrayal of Africa as a relative outsider to pollution and industrial waste has motivated a perverse logic that it can (and, in fact, should) absorb more toxicity, as in Lawrence Summers' famous memo advocating the "impeccable economic logic" of offloading more toxic waste to Africa (see Nixon 2011). More broadly, the frame of an underpolluted, nonindustrial Africa buttresses the dominant belief-both within and outside of Africa-that increased pollution is a worthwhile and necessary price to pay for development. However, recent critical interventions (Hecht 2012; Livingston 2012) argue that this perspective renders invisible the toxicities that African bodies and landscapes have already experienced and continue to experience as a result of their colonial and postcolonial incorporation into circuits of global capital accumulation.

In this article, we extend this critique to the case of agricultural pesticides, where the logic of an underpolluted Africa in need of development is particularly prominent. We focus our attention on Sub-Saharan Africa (SSA), ${ }^{1}$ where there is a widespread conception that farmers are "organic by default" (as noted by Andersson and Isgren 2021) or "too poor to pollute" (Kütting 2003), despite substantial and growing evidence to the contrary. During and after European colonization, many SSA states actively promoted agricultural development, often incorporating pesticides into their plantation systems and modernization projects (Ajayi et al. 2009; Zinyama 
1992). After World War II, rising imperial powers-especially the United States-worked industriously to open markets across the continent for toxic substances to be inserted into smallholder cash cropping. Pesticides figured prominently in the burgeoning apparatus of foreign aid over the past half century (Weir and Schapiro 1981), while structural adjustment programs and ongoing trade liberalization have increased access to chemicals (Haggblade et al. 2017; London et al. 2002). Agroindustry players have long justified pesticide promotion as indispensable to African food security (see Fouilleux et al. 2017), which persists in today's initiatives for a "New Green Revolution" among smallholder farmers ${ }^{2}$ and larger-scale commercial farms in Africa. These renewed efforts to increase agrochemical availability remain anchored in the belief in the formula that more chemicals equal higher yields and household incomes. Moreover, pesticides (alongside other agricultural technologies) serve as a technoscientific fix for an ever-widening array of "development and sustainability" issues, including the empowerment of women, rural migration, addressing climate change, and conservation through intensification in delimited areas of production (Büscher and Fletcher 2020; Moseley et al. 2017; Patel 2013; Schnurr 2019; Shilomboleni 2020).

Agrochemical use by smallholder farmers has been rising in the past two decades, in particular with significant global funding from agribusiness corporations, international organizations, and donor countries of the Global North (D'Alessandro and Zulu 2017), a growth that has been exacerbated by rising influence of emerging powers of the Global South. Chinese chemical manufacturers, especially, inundate African markets with cheaper brands and generics through South-South technology transfers, trade deals, and informal routes (Bräutigam 2009; Haggblade et al. 2017; Shattuck 2021a). Meanwhile, smallholder farmers have reached a crossroads with agrochemicals as both necessity and risk, potential and peril. Many farmers identify pest and weed management as a predominant constraint in their farming systems, particularly given increasing labor shortages (Andersson and Isgren 2021; Luna 2020). Herbicides, in particular, offer a quick and relatively inexpensive option for replacing the arduous, injurious, and time-consuming labor of manual weeding. Hired or in-kind labor among kin and neighbors is, in many places, no longer abundant or cheap, as laborers grow scarcer as a result of rural exodus to cities, competing off-farm employment, and parents putting children in school (Fairet et al. 2014). This also generates gendered burdens, as weeding has long been considered "women's work" across many African countries. Moreover, as farmers scramble for solutions to intensifying pest infestations that accompany environmental and climate change, pesticide use is poised to escalate further (Andersson and Isgren 2021).

However, this boom in pesticides has not been matched by efforts to mitigate or reduce risks. Regulation and monitoring of pesticides and pesticide-related illness in most of SSA is woefully underfunded, understaffed, absent, or ineffective (Lekei et al. 2017; Mengistie et al. 2015; Rother et al. 2008). This has resulted from decades of neoliberal rollbacks to state funding and government regulation (London et al. 2002; Tousignant 2018), as well as from the pesticide industry's promotion of "safe use" strategies. Projects to educate and support farmers in agroecological farming and integrated pest management practices are not only anemic, but also coincide with competing agrochemical paradigms advanced by state institutions, extension agents, pesticide vendors, and nongovernmental organizations (Stein 2021). Therefore, while pesticide use is often lower in SSA than in many contexts of industrialized agriculture, there are nonetheless serious concerns-shared by experts, activists, and farmers-about rising rates of acute poisoning, ecological devastation, and unknown effects of long-term exposures and residues (De Bon et al. 2014; Negatu et al. 2016; Sankoh et al. 2016; Williamson et al. 2008).

This article begins by reviewing social science literature on pesticides in SSA, which we see as offering two important frames for understanding pesticide use in SSA that go beyond the 
dominant framing of agrochemicals as necessary for productive agriculture, farmer food security, and climate adaptation. Our method of reviewing literature began with a series of search terms and combinations (e.g., pesticides, herbicides, agrochemicals, toxicity, Africa) in Google Scholar with the time frame 1900-2020. We worked through the bibliographies of key papers, read papers recommended by colleagues, and pulled out key themes in the social science contributions. We found that the social science literature largely employed two main frames, or ways of thinking about pesticides and their use: (1) structural violence; and (2) invisibility issues related to limited perception/knowledge and illegibility.

The first frame highlights the legacies of colonial histories and violence (Nading 2020), considering how African bodies and landscapes have been (already) polluted by agents and structures of imperialism, capitalism, and quasi-religious fervor for technology-driven "progress." The second (sometimes overlapping) frame has highlighted the myriad problems of invisibility (of pesticide use in general, of limited knowledge about pesticides and their toxicities) and the production of ignorance by state and industry. Pesticides themselves are often illegible as they permeate-untraced-through regulatory frames, borders, bodies, and ecosystems (Boudia et al. 2018). The extraordinary uncertainty of linking pesticides with illness across time is a well-established epistemic challenge (Brown 2007; Nading 2020; Shattuck 2020). Farmers, scientists, and regulators alike struggle to "know" the precise risks of pesticide use. This is particularly vexing in the Global South, where resources allocated to toxicological and related research can be severely limited (Tousignant 2018).

Yet, a challenging and marginalized dimension of toxic exposure in African contexts, we argue, is the use of pesticides by smallholder farmers who actively bring chemicals into their own (and others') bodies. The tension between the drive for development versus concerns about toxicity is not only a policy-level debate for African states, but also an embodied tension for pesticide users on the ground. That is, pesticide use is a central struggle for smallholder farmers faced with "trading health for income" (similar to the pesticide vendors in Rother 2016), and agentively utilizing chemicals, though not-as Marx famously wrote-in conditions of their own choosing. It is this interplay between structure and agency, mediated by farmers' bodies, that we highlight as a key gap in the literature and that we believe is a fruitful new direction for scholarship on pesticides in SSA.

This article is informed by insights that emerged inductively from our respective ethnographic projects in Mozambique and Burkina Faso, where we observed people not necessarily struggling against pesticides, but rather bringing pesticides into their worlds and holding in tension the destructive and generative possibilities of agrochemicals. We began to notice the sensory descriptions that had accumulated in the marginalia of our field notes, yet our observations did not easily fit with the academic literatures on hand. We thus propose a needed complement to the literature that attends to farmers' bodily knowledge and experiences of chemical exposure-the "toxic sensorium"- unfolding amid Africa's agrochemical proliferation. Pesticides and their related toxicities may be invisible in some regards, but for farmers applying them, pesticides are highly visible and tangible. This, we argue, is of particular importance among farmers who handle pesticides daily, observing the scents, tastes, and textures of chemicals in immediate ways that shape how they engage with chemicals, but that also shape their notions of self and redefine parameters of resistance and accommodation.

The "toxic sensorium" as elaborated elsewhere (Chen 2011) brings attention to the set of affective states and phenomenology in the context of toxic worlds where injurious chemicals may be simultaneously feared and desired. To this, we add that chemical interdependencies in African contexts may not solely be destructive of life, but also constitutive of new ways of living. Scholarship on co-productions of toxicity and colonial, imperial, and capitalist struc- 
tures of power should also examine toxic subjects' specific relationships to economic opportunity, performances of self and modern subjecthood, and gendered models of achievement. As a complementary view to the dominant framings, this sensory approach holds space for greater complexity of African rural subjectivity within interstices where people may apprehend environmental and bodily harm from toxic exposure and yet use pesticides anyway-thereby generating future directions for research on emerging participation in agrochemical expansion. These insights can also inform policy efforts that seek to reduce pesticide use or that rely on educating farmers in "safe use" but that often fail to apprehend farmers' embodied practices and performances.

In the following section, we recount the rise of agrochemical usage in successive projects of economic expansion that placed SSA farmers at the forefront of toxic vulnerability. We then trace the growing literature on how agrochemicals are currently being used across the continent, who is being exposed, and failures of regulation. We highlight how a focus on "knowledge deficits" and "safe use" education of small-scale farmers can render them responsible for toxic exposures while downplaying deeper structures and causality. Finally, we draw on our own ethnographic research in Burkina Faso and Mozambique to illustrate how smallholder African farmers live with pesticide toxicities amid affective and sensory attunement with chemicals. Ultimately, we build upon existing frames of structural violence and invisibility; yet by focusing on embodied experience, we open up new questions about how farmers are indeed structurally constrained while they may also actively embrace pesticides-even amid knowledge and awareness of their toxic harm.

\section{Colonial Residues}

The very characteristics that made agrochemicals attractive for widespread adoption across the past century-their cheapness, stability, and persistence-also render them hazardous and enduring linkages to colonial and imperial efforts to control people and nature. Ann Stoler contemplates the transition from colonization to the postcolony not as a sharp rupture at independence, but as the "hardened, tenacious qualities of colonial effects" (2016: 7) that have protracted afterlives and cumulative layers. Similarly, "slow violence," for Robert Nixon (2011), operates by unleashing toxicities in successive drives that accumulate into social exclusions that render groups invisible, along with the chemicals that harm them. The work of excavating the structural violence underlying toxicity helps to reconnect global perpetrators to sites of contamination and victimization when these connections are so easily obscured and forgotten. Here, we briefly trace the "slow violence" of the rise of agrochemicals across SSA.

The 1930s saw the beginning of the era of synthetic organic compounds, with the discovery in 1939 of the insecticidal properties of dichlorodiphenyltrichloroethane (DDT). DDT soon took center stage as a vehicle for imperial domination of nature, featuring prominently in pest control programs against human and livestock diseases, and transforming malarial zones into productive farmland after the agricultural utility of pesticides was demonstrated in Italy and Germany in World War II (Hambleton 1955). DDT use in agriculture began sporadically through colonial partnerships for commodity export, including cotton in Uganda from 1945 (Ingram and Davies 1965); maize in Southern Rhodesia from 1946 (Doro and Swart 2019); and tobacco in South Africa from 1948 onward (Moran et al. 2013). By 1950, an array of pesticides developed in Europe and the United States were being used widely, notably the persistent organic pollutants aldrin, dieldrin, and DDT. As vehicles for US imperialism on the continent, pesticides featured in the rise of bilateral agricultural development programs in the emergent 
American foreign aid apparatus. US scientists partnered with organizations such as the United Nations Food and Agriculture Organization (FAO) seeking to increase general acceptance of agrochemicals among African farmers, making the chemicals attractive through cheap prices and thereby opening markets for American chemical products (Hambleton 1955; Kay 1950). Scattered evidence across the continent at this time points to use of pesticides in many zones, as by the 1950s pests began exhibiting signs of chemical resistance (Wiese and Bot 1971).

While the rise of farmworker and environmental movements in the 1960s and 1970s in the Global North made the "unknown" hazards and harms of pesticides known to the public, it is worth noting that the scientific community had been wary of toxicity from the start of global pesticide dissemination (WHO 1956). This is an important departure from the idea that toxic impact on bodies and ecologies was an eventual discovery. The risks of accumulated toxicity were discussed at length in early meetings of the Expert Committee on the Toxic Hazards of Pesticides to Man convened by the World Health Organization (WHO) annually over 12 years, beginning in 1951. Scientists were dispatched across the world to collect case studies on apparent toxicities for the report. One of the commissioned studies, for example, was an analysis of exposure to dieldrin in Tanganyika that notes how protective overalls given to chemical sprayers, even when washed properly as instructed by experts, still accumulated pesticides daily. This was leading to pesticide buildup inside operators' homes and dangerous exposures to women clothing-washers. From this relatively early date, scientists had warned that clinical signs of acute poisoning from spraying might be absent, even though chemical accumulation would pose chronic harm (WHO 1956). Nevertheless, the overall WHO report concludes that pesticides did not appear to represent an "immediate or serious threat to human health," even as the discussion section lays out the near impossibility of ensuring proper use in many parts of the world through "constant surveillance and observation." The history of Senegalese colonial cotton growers is just one prominent case that similarly illustrates contradictions over introducing chemicals into smallholder farming (Hardin 2020). Reports from imperial agronomists urging precaution were overridden by administrators' blithe insistence on chemicals as modern, beneficial, and necessary. Thus, from the start agrochemicals became a "necessary wounding" (Shannon Cram quoted in Nading 2020: 213), where "minor" harms were overridden by profit motive in the short term, and toxic effects in the long term would be evaded and disavowed.

In the 1960s and 1970s, as many African countries embarked upon independence, pesticides were conscripted (though unevenly) into nation-building projects toward protecting and expanding domestic agricultural production. In various parts of socialist East and Southern Africa, villagization programs tightly controlled smallholder production in outdoor "laboratories" nearby agricultural research stations, where farmers were made to adopt modern practices and inputs (Bowen 2000). Foreign interests in many contexts also retained their colonial presence in new guises with the expansion of foreign inputs and agrochemicals. This was especially the case in Francophone West African countries, where the French colonial state perpetuated coercive cotton production by fostering African partnerships with French agribusinesses (Dowd-Uribe 2014) in attempts to retain their former shares in state cotton companies.

Meanwhile, emerging global surveillance of pesticide exposures in this period gave early indications of trouble. The incidence of primary liver cancer in countries such as Mozambique was estimated to be the highest in the world in the 1970s (Bababunmi 1978), with a suspected synthetic chemical etiology. Pesticides were linked to devastation of honeybee and aquatic populations for the first time through chemical runoff (Chandler 1976). Parathion, which was widely used due to its low price and high biocidal power, caused epidemics of toxic poisoning by entering the food supply, as it did in Sierra Leone in 1986 (Etzel et al. 1987). An International Development Research Center report, “Necessary but Dangerous Poisons” (Forget 1989), calcu- 
lated two million annual acute poisoning events in developing countries in this period, with the incidence of pesticide poisoning 13 times higher than rates in industrial countries.

Yet, many Global North countries at the forefront of expressing concern with Africa's contamination were also perpetuating inequalities and facilitating toxic spread. This is perhaps most strongly illustrated in the treatment of Africa as a receptacle for offloading obsolete and banned chemicals from Europe and the United States in the 1980s and 1990s. Scholars categorize this insidious export of waste to Africa as "toxic colonialism" (Clapp 1994; Lipman 2002; Livingston 2012). By the early 1990s, 6,500 tons of banned and obsolete pesticides had been identified across 20 African countries, though the estimated total figure for Africa ran into the tens of thousands (Ferrer and Cabral 1991). Proposals to manage waste were also hotly contested, such as the Danish International Development Agency's plan to retrofit a cement kiln in Mozambique to become a hazardous waste incinerator (FAO 1999). Although over 300 tons of unidentifiable pesticides were to be destroyed, Mozambican civil society rejected the plan. They warned that the seemingly beneficent plan would render Mozambique a future dump site for Denmark's toxic waste, compelled to destroy chemicals using polluting methods already prohibited in Europe.

Obsolete pesticides continued to be discovered with alarming regularity across SSA, abandoned near farm fields, homes, and water sources, without clear "owners" responsible for their disposal (Balayannis 2019; Dalvie et al. 2006). Even recently, efforts to ban the international trade of pesticide waste are fraught, while the World Bank's African Stockpiles Programme has achieved only modest environmental remediation. Newer generations of agrochemicals are also on the rise, including neonicotinoid pesticides and succinate dehydrogenase inhibitors (SDHIs). These chemicals were designed to be less toxic to humans, birds, and mammals than older pesticide groups (carbamates and organophosphates), yet they show the ability to penetrate plant systems extensively, and are capable of spreading even further into the environment than the chemicals they were meant to replace (Sorensen et al. 2015).

Thus, the past century of agrochemical dissemination in SSA reveals the "slow violence" of pesticides unfolding in toxic continuities across colonization and foreign aid, postindependence state-building, and neoliberal extractivism. Pesticides deployed in service of foreign and elite interests lay waste to African bodies and environments while perpetuating global structures that erase responsibility.

\section{Pesticides in Africa Today: Invisibilities and Not-Knowing}

If a central problem of the "slow violence" of pesticides is invisibility, the antidote becomes visibility. In many ways, recent literature on pesticides in SSA-much of it in occupational health-has provided this response. Here, we outline key findings of this literature, which has helped bring to light the extent of pesticide use in SSA as well as the numerous institutional and regulatory failings in this regard. Despite these significant contributions, much of this literature focuses on insufficient information and safety practices that result in harm. Like other efforts to address environmental problems through knowledge campaigns and individual responsibility (MacKendrick 2018; Wiebe 2016), this approach can overemphasize agency and overlook the robust finding that, even when farmers know, they still engage in risky practices (Andersson and Isgren 2021; Andrade-Rivas and Rother 2015; Galt 2013; Lekei et al. 2014; Luna 2020; Shattuck 2021b). We offer our approach to this puzzle in the final section of the article.

Empirical studies of pesticide use in SSA have been amassing over the last two decades. Country-level studies have documented rising rates of pesticide use and the widespread presence of 
unregulated (and often highly toxic) chemicals and unsafe practices (e.g., Burkina Faso: Bayili et al. 2019; Luna 2020; Ethiopia: Gesesew et al. 2016; Negatu et al. 2016; Ghana: Aidoo et al. 2019; Nyantakyi-Frimpong et al. 2016; Mali: Haggblade et al. 2017; Nigeria: Tijani 2006; Sierra Leone: Sankoh et al. 2016; South Africa: London 2003; Rother et al. 2008; Tanzania: Lekei et al. 2014; Ngowi et al. 2016; Stadlinger et al. 2011; Uganda: Andersson and Isgren 2021; Muleme et al. 2017). Other literatures have documented pesticide residues and markers of toxicity on produce and in human bodies and ecosystems across the continent (see Sheahan et al. 2017).

Many of these studies point out the pervasive "invisibility of health and safety problems" (Rother et al. 2008) given the widespread focus on African agricultural productivity. While concern may be rising about male farmers' exposure to pesticides (i.e., through improper spraying practices and the failure to use personal protective equipment, or PPE), a narrower literature has highlighted exposures among other groups, such as farmworkers (London 2003; Ngowi et al. 2016), informal pesticide sellers (Rother 2010), African consumers, young people, and women (Nyantakyi-Frimpong et al. 2016). The gendered dimensions of pesticide exposure have been particularly "out of sight, out of mind" (London et al. 2002). Again, just like the impression of Africans as "too poor to pollute," women are often overlooked as pesticide applicators (London et al. 2002; Naidoo et al. 2008), yet face particular risks and exposures. Women are often responsible for weeding, thinning, and harvest activities, and frequently re-enter fields directly after spraying, increasing their exposure (Ngowi et al. 2016; Nyantakyi-Frimpong et al. 2016). Women often have lower literacy levels and less income, making them potentially less able to read labels or purchase PPE (Naidoo et al. 2008). In many parts of Africa, women are responsible for laundering the family's clothing, which can be soaked with pesticides (Mrema et al. 2017); meanwhile, laundering is ignored in some "safe use" and PPE trainings.

\section{Regulatory Invisibilities}

Even where problems are visible, they are often unaddressed. It is widely observed that "major gaps exist between pesticides policy on paper and its implementation in practice" (Mengistie et al. 2015). There are numerous national, regional, and international regulations and policies that seek to limit and monitor the flow and types of agrochemicals entering African countries, most notably the Rotterdam Convention on Prior Informed Consent (which entered into force in 2004). The complexities and challenges with these regulatory efforts lie beyond the scope of this article. Here, we highlight the problem of invisibility in regulatory challenges, noting how pesticides and their harms flow untraced across and through borders, bodies, and ecologies, even when serious efforts to trace them are being made.

Many state officials admit they cannot surveil and enforce regulations, starting with the cross-border trade of unregulated chemicals, which are often of dubious quality (Williamson et al. 2008). A consistent finding across the continent is that farmers are using (and salespeople are selling) illegal, unregistered, or banned chemicals, and that sellers are frequently repackaging chemicals into smaller quantities in unmarked containers (Bayili et al. 2019; Gesesew et al. 2016; Ngowi et al. 2016; Rother 2010; Sankoh et al. 2016; Tijani 2006; Williamson et al. 2008). There is thus a substantial gap even in tracing the quantity, types, and provenance of pesticides used in African agriculture.

Regulations in the realm of occupational safety have also failed to protect farmers and workers. Where they exist, these rules often fail to apply to the settings or categories of small-scale farmers and farmworkers (Rother et al. 2008). Farmers are often unaware of regulations, or regulations are simply unenforced. In other cases, farmers and farmworkers are not included (they are left invisible) in occupational health and safety regulations or compensation systems 
(Ngowi et al. 2016). Furthermore, healthcare systems are inadequately prepared to deal with acute pesticide poisoning, as health workers are not trained in recognizing or treating pesticide poisoning (Lekei et al. 2017). Acute pesticide poisonings are widely underreported, and the scale of the problem thus remains invisible (Lekei et al. 2016), while the problem of chronic pesticide poisoning remains almost entirely undocumented and unaddressed. These shortcomings are rarely the fault of individuals within these systems, who are working hard with limited resources (e.g., toxicologists; Tousignant 2018). Many of these shortfalls can be traced in part to the neoliberal era of structural adjustment programs that shrank state budgets across the board-from agricultural research and extension, to health services-all of which were justified in the name of economic growth.

It is worth pointing out that even if regulations and regulatory agencies were substantially more powerful, they would still face extraordinary hurdles related to the unknown and endlessly multiplying uncertainties of how/to what extent/in what quantities/in what circumstances/for whom/at what time scales chemicals cause varying types of harm in interaction with other chemicals, diseases, ecologies, and bodies that are porous and ecologically intertwined with the world around them (Livingston 2012; Roberts 2017; Shattuck 2020). This is what Annie Shattuck (2020) calls the "agnogenic" (ultimately unknowable) nature of agrochemical risks-which underscores the limits of scientific regulatory approaches that demand and ultimately depend upon particular forms of knowability and certainty.

It is also significant to highlight the chemical industry's role in producing ignorance. Corporate interests, including those of agrichemical companies, are adept at creating and promoting uncertainty, doubt, or strategic ignorance in order to continue to sell their products (McGoey 2019; Oreskes and Conway 2011). For example, Crop Life Africa (the global agribusiness industry's public relations arm) regularly disseminates shockingly blithe media reports that maintain that pesticides are used properly, and that they are therefore perfectly safe. ${ }^{3}$ Agribusiness also tends to employ narrow and technocratic models of expertise to evaluate their products while ignoring other forms of knowledge that might challenge their claims (Luna and Dowd-Uribe 2020). Furthermore, chemical companies keep important data restricted under the rubric of "trade secrets" and "confidential business information," further limiting broader knowledge of potential toxicities.

\section{Farmers and Pesticide Literacy}

In addition to lacunae in official statistics, monitoring, and scientific knowledge, recent literature on pesticides in Africa often focuses on pesticide users' and vendors' lack of knowledge: the inability to read labels, lack of knowledge about pesticides, improper practices (e.g., the improper mixing of chemicals), failure to understand or use PPE, the improper storage and disposal of chemicals and their containers, reusing containers, and failing to seek help for pesticide poisonings (Gesesew et al. 2016; Rother 2010; Sankoh et al. 2016; Stadlinger et al. 2011; Tijani 2006). Some studies do recognize significant barriers to farmer behavioral change, including cost and access barriers for PPE and the difficulty of using PPE in hot temperatures. Other authors have highlighted state-level and structural drivers that place the burden of risk on farmers, including "market liberalization, poor regulation enforcement, and persistent neglect of agricultural extension" (Andersson and Isgren 2021), and a failure to provide support for less pesticide-intensive agricultural practices and technologies (Ngowi et al. 2016).

Despite these criticisms, the idea that insufficient knowledge is a primary cause of toxic exposure has been promoted for decades by the global pesticide industry in order to frame pesticides as safe (Murray and Taylor 2000). This approach includes "safe use" campaigns, emphasis on 
pesticide labeling (noted in Rother 2018), and the general idea that proper use of PPE can prevent most harm. Although PPE should be the final option in the "Hierarchy of Control" model of controlling exposures to occupational hazards, it has long been the first option recommended and most focused on by industry (Andrade-Rivas and Rother 2015; Murray and Taylor 2000). Part of this approach may result from pragmatically minded practitioners (such as extension agents) who see little hope in addressing deeper structural inequalities and regulatory failure, and simply want to help farmers reduce their risks. Yet focusing on knowledge and farmer behavior displaces the burden of responsibility onto the user, and corresponds with the broader neoliberal shift to push environmental responsibilities onto the voluntary and informed actions of individuals (MacKendrick 2018; Wiebe 2016).

With respect to pesticides, this frame results in a widespread belief among government, academic, and civil society stakeholders that "pesticides are inherently safe" and that "problems only arise from the errant behavior of individual farmers," as Hanna-Andrea Rother and colleagues describe in South Africa (2008: 416). Yet even with proper PPE use (itself rare), chemicals still pose a problem. Recent research challenges the very efficacy of PPE in protecting workers from agrochemicals, pointing out the incredible complexity of matching chemicals to the proper PPE materials, proper use, cleaning, and removal (Garrigou et al. 2020). In addition, and more to our point, there is substantive evidence (in Africa and beyond) that knowledge alone does not mitigate farmers' risk and that it does not necessarily change behavior (Andrade-Rivas and Rother 2015; Galt 2013; Lekei et al. 2014; Luna 2020; Muleme et al. 2017; Shattuck 2021b). These findings challenge the linear assumptions made by "knowledge, attitude, and practice" studies that inform public health interventions.

We find it particularly useful to draw a parallel here with insights from critical health literature on HIV/AIDS in Africa. This field has also amassed substantial evidence for the limitations of behavioral interventions based on information and reasoned persuasion. Mainstream literature and public health initiatives have often focused on informing individuals in order to change their behaviors to reduce the risk of HIV infection. However, critical sociologists and cultural anthropologists have questioned this approach, pointing out (1) the flaws (and underlying racism) in assuming that individual practices are really the problem (Biehl 2007; Hunsmann 2016; Stillwaggon 2006), and (2) that cultural, political, economic, even ecological factors significantly shape behavior (Biehl and Petryna 2013; Mojola 2014). The focus on individual behaviors leaves invisible the structural inequalities that both underlie disease transmission and that are (re)produced by intervention efforts (Hunsmann 2016). Knowledge and information may be necessary components, but are insufficient for change (Parkhurst and Hunsmann 2015).

This contextualization of the limits of knowledge-based approaches can usefully inform the current impasse regarding "safe use" approaches to farmers' pesticide practices and the widespread belief that if pesticide toxicities could simply be known and made visible, problems could be largely solved. Part of this problem stems from the knowledge-based approach promoted by the pesticide industry. Yet we also contend that pesticide users themselves are caught in complex tensions (in SSA as elsewhere: Flachs 2019; Luna 2020; Shattuck 2020; Shilomboleni 2018). One component of this results from the structural constraints and drivers of pesticide use. Agrochemicals are increasingly cheap and available in the marketplace (Haggblade et al. 2017), and this is largely a result of trade liberalization and structural adjustment programs (London et al. 2002). Monocrops, heavily promoted by governments dependent on export income, has also increased pests (Mrema et al. 2017). Additionally, intertwined pressures of debt and culturally related declines in labor supply can drive pesticide use (Luna 2020). These structural constraints and influences on farmer behavior indicate that knowledge alone is not the problem, and that it is therefore not the solution. 


\section{The Toxic Sensorium}

Amid pesticides' many invisibilities, and amid the many projects to make them once again visible, we highlight a critical gap in social science research: the ways pesticides are often tangibly felt and sensed in farmers' lives. This includes the heavy weight of a full backpack of sprayer rubbing at farmers' backs as they walk miles through their fields, the acrid smell wafting in the air from jerry cans, the headaches and runny noses after spraying, the stinging eyes and skin rashes, and the stickiness of residue on the skin. Yet embodied experiences are not solely undesirable. In our ethnographic research with farmers, we have noted how chemicals become tangled in farmers' lives in small and perhaps surprising ways: in Burkina Faso, farmers enjoy unfolding their tired bodies into reclining chairs after a quick herbicide application relieves them of a long day of hand-weeding. In Mozambique, farmers breathe in what is literally called the "smell of success" given off by pesticides, now intimately tied with smallholders' commercialization and accumulating profits.

Recent work in political ecology (and political ecologies of health) has begun rethinking the fluidity between bodies and broader ecologies, considering humans as inseparable from their surrounding environments and as themselves complex ecological systems ("embodied ecologies"), an approach that offers important insights for understanding experiences of toxicity (Nyantakyi-Frimpong et al. 2016; Shattuck 2020; Valdivia 2018). In addition to this reframing, Andrea Ford (2019) and others across many fields (see Hockey and Allen-Collinson 2009) have emphasized the need to pay further attention to the materiality of bodies and to pay closer attention to the "sensorium" of the working body. This includes "carnal ethnographies" of the sweaty, painful, joyous experiences of bodies themselves (i.e., Little 2019; Luna 2019). Such an approach overlaps in some ways with important research done by ergonomists and ergotoxicologists (i.e., Garrigou et al. 2020), yet also explores the affective dimensions of embodiment and how bodily practices, performances, and experiences are entwined with notions of status and identity (Flachs 2019; Mojola 2014).

Literature on pesticide use in SSA could also draw on related scholarship on chemicals and toxicity that puts the "sociality" and complex embodied experiences of chemicals on the agenda, through work on toxic encounters (the "minor enfeebling encounters ... that stir ethical consideration and potential intervention" (Shapiro 2015: 369)); examinations of sensory epistemologies or "regimes of perceptibility" (Spackman and Burlington 2018); and other phenomenological experiences of toxicity. Michelle Murphy (2017) invokes the notion of "alterlife," pointing out that we all live in chemically altered ecologies/bodies. Shattuck (2020), too, in the context of Asia, highlights how pesticides help to "create a life worth living," despite growing awareness and experience of toxic exposure. "Agrichemicals might have been a positive force in [a farmer's] life for some years, and we can acknowledge this," Shattuck writes (2020: 10), "without letting go of the injustice of an agrarian system in which exposure is a condition for making [their] way through life." Mel Chen (2011) has described the "toxic sensorium" as a set of new intimacies, affective states, and memories that emerge for people suffering with heavy metal poisoning. This work marks an important shift in attending to the sensory memory of objects, affects, and bodily knowledge that renders toxicity visible. This asks us to consider that an array of chemical products, from perfumes to cleaning products, contain toxins that spread far and wide, yet are encountered by many as benign and pleasurable.

Drawing on our respective ethnographic research in Burkina Faso and Mozambique, we advance the "toxic sensorium" as an apt approach to toxicity in Africa, where chemical relations extend beyond those portrayed exclusively in terms of illness, disruption, and destruction. We 
seek a more complex, textured understanding of the ways people bring chemicals into their worlds. We do this to avoid framing farmers as either witless victims or as villains, and with the goal of informing policy discussions (i.e., of pesticide education campaigns, regulation efforts, or attempts to reduce pesticide use), to better understand why and how farmers bring these chemicals into their lives. Crucially, observations of the sensorium arise from intimate, embodied knowledge that comes through planting, weeding, eating, washing, and other everyday experiences. By exploring how pesticides can maintain ways of life and enable new experiences and statuses among farmers, we propose new directions for inquiry that further develops farmers as multidimensional-rather than as essentialized and homogeneous-actors in African agrarian life. These more nuanced understandings are, we feel, essential for informing public policies related to pesticides. We explore what this approach looks like through two community vignettes (drawing on broader ethnographic research projects) of the "toxic sensorium" in Burkina Faso and Mozambique.

\section{Burkina Faso}

While Burkina Faso cotton farmers have used pesticides since the 1970s, pesticide use has expanded significantly in the last 15 years, with greatly increased herbicide use and broader pesticide use in food crops. Despite regional and national-level regulations, many highly hazardous and illegal pesticides are in widespread use and cheaply available in markets (Bayili et al. 2019). Current pesticide practices in Burkina Faso raise concerns similar to those across the continent: that farmers and farmworkers (including men and women, but very often younger men) mix and spray highly toxic compounds without PPE, that families drink water from streams near fields, and that they reuse pesticide packaging, resulting in long-term and cumulative exposures with uncertain consequences for both human and ecological health.

Jessie Luna conducted eight months of ethnographic fieldwork in 2016 in the southwestern Houndé region, undertaking 125 interviews (in French and the local language Dioula; both are languages that she speaks fluently) and five months of participant observation in a rural community (Luna 2018). This fieldwork revealed the complex tensions farmers navigate, where pesticide use can feel highly agentic - a path to development and modernity-yet at the same time crushingly determined and perilous. Pesticides can wrap farmers in a cloud of compulsion and anxiety. Farming with chemicals, tractors, and new technologies is widely seen as an absolute necessity, not a choice, given severe labor shortages and economic pressures to increase income (Luna 2020). Many farmers explained that they simply could not farm without chemicals, despite the fact that smaller-scale farmers are often indebted by purchasing these chemicals, and some (though certainly not all; see Luna 2018) are anxious about toxicity and the unknown consequences of exposure.

For example, Luna recalls a warm moonless night, sitting with a woman in her 50s inside her small bedroom. The woman had worked all day in her brother-in-law's cotton fields (a 10-mile bike ride away), as she had for the weeks and months and years before. Her shoulders and eyes hung heavy with exhaustion. When Luna asked her about her thoughts on pesticides, she felt her shrug. "People can't farm without pesticides anymore." She explained that pesticides are why the farms have gotten so much bigger, because farmers faced new expenses and debts, and wanted to expand their acreage, but they also faced major shortages of labor. The only way to increase production in this context was to use herbicides (see Luna 2020). She then added: "It's why we're all sick, even dying. We know they are making us sick, but what can we do? We don't have a choice. We're just trying to get by, and we can't farm without them. It is just too exhaust- 
ing." They sat in silence, as the weight of her words hung in the air like an invisible cloud of chemicals. We know we are killing ourselves, but we don't have a choice. Yet, she seemed resigned to accept the risk of chemicals for the brief respite they afforded.

At the same time, chemicals represented-for many people in the region-a horizon of hope and progress. Many (not all) people strongly desired modernity and development, which in the Dioula language is expressed as "getting out of the dirt" ( $k a$ bo nogo la). Modernity and development, then, literally mean an escape from the dirt and the physical labor of traditional farming-which is often racialized as "black" (farafin) and lower status, rooted in deep historical connotations of forced labor and exploitation from the colonial era (Luna 2018). Tractors, motorcycles, and pesticides operate not only as status symbols of a modern and successful farmer; they also help farmers inhabit a new embodiment: literally standing up from being bent over with a short-handled hoe. "We no longer farm with our backs," Luna was told repeatedly, as farmers proudly showed her their pesticide sprayers. This new embodiment was seen by many farmers, both men and women, as a path of liberation.

Agrochemicals were thus becoming a tool for escaping the drudgery and low status of endless weeding, offering (though not always delivering) new possibilities: the promise of higher income and time to recline in a chair outside of a new cement house. Ultimately, this vignette reveals how framing pesticides solely through "invisibility" misses the reality of some farmers' embodied desires for agrochemicals - albeit amid mixed concerns about toxicity—as a part of a path toward upward mobility.

\section{Mozambique}

Serena Stein conducted two years of ethnographic fieldwork in northern Mozambique's interior from 2015 to 2018, living and farming in Lomwé smallholder communities along the borders of new foreign plantations. At the porous boundaries of Lomwé farmlands and agribusinesses ${ }^{4}$ materializing with investments in the Nacala Agricultural Growth Corridor (Stein and Kalina 2019), pesticides were increasingly seeping beyond plantation enclosures. Community members working for plantations sometimes smuggled jerry cans filled with agrochemicals into villages for use on their own farm plots. Some plantations also initiated outgrower programs with the community, supplying pesticides among other inputs like seeds and fertilizers. Empty containers were commonly reused by children to fetch water for drinking, cooking, bathing, and to store home brews. During windows of intensive spraying on the plantation, villagers reported that their own fields were often queimado, or burned, by chemical drift. People also talked about their skin feeling sticky with dust and residue, attributing eruptions of rashes and lesions to agrochemicals even weeks and months later. Periodically concerns were raised at community meetings with leaders, who then wrestled with reporting complaints of exposure to local government officials. This, they capitulated, were the costs of development. Moreover, the biggest increase in pesticide exposure, they argued, came from smallholder farmers themselves.

This made sense, as there was an emerging cohort of commercial farmers, emergentes, that began to fuse the notion of becoming model farmers with the embrace of agrochemicals. Various foreign-aid-funded programs were layering in the landscape, focused on cultivating a soybean boom by financing tractors and creating value chains for farming inputs (Stein 2021). The emergentes were often handpicked by development projects, and primarily comprised of middle-aged men with ambitious young sons poised to become benchmarks for the community. These farmers were said to have the cabeça ("to have the brains," in Portuguese) to handle a diverse portfolio of crops, to manage farm laborers, and especially to reinvest revenues from 
commodities into chemical-heavy horticulture (Melo et al. 2019; Sitoe et al. 2017). The average annual volume of pesticide imports to Mozambique expanded fivefold over the past decade, leading to 90 percent of horticultural farmers, in some cases, using "highly toxic" 5 chemicals with astonishing regularity (Snyder et al. 2018). This has taken place even as the WHO and the FAO have been working since 2012 to cancel the registration of dozens of chemical products in Mozambique used on staple crops.

Lino, a young man in his 20 s, was among those selected as an emergente, as the son of a prominent commercial farmer and transporter of grain. Lino's promise as a modern farmer was also intertwined with deeply rooted inequalities, as his father had been an assimilado granted certain land tenure and educational privileges by the authorities during the colonial era (Bowen 2000). While other young men his age provided casual labor (ganho ganho) on his fields, Lino still made sure that he returned home each day dirtied with soil, sweat, and chemicals as material evidence of his dedication to the project of farming at increasing scales. In one memorable encounter, Stein followed Lino along a large plot being prepared for tomatoes. Lino was attentive to every detail, kneeling next to the ganho ganho workers, and inspecting the soil, the seeds, and their actions. "You can't trust the ganho ganho," he said, when it came to complex tasks like mixing the chemicals or configuring the sprayer backpack. He was fastidious, under the pressure to uphold new standards of farm management and integrate modern practices. This, Lino explained, required taking on the risky tasks you might want to pass on to laborers.

Pesticides clung to Lino's clothing after a long day on the farm, giving him a cheiro de sucesso, or the "smell of success," as he called it. Other young men in the community spent their days idle or they abandoned rural villages to work odd jobs in the town margins. Lino was busy becoming, however, a promising young man: one who intended to stay close to the soil by pursuing agriculture as a modern and lucrative livelihood. The chemical cheiro wafting from his shirt, skin, and hair was the sensorial evidence of an industrious spirit. The cheiro tied the danger of exposure to values of sacrifice, which played an important role in the emerging ideal of masculinity for these young farmers. That is, Lino demonstrated his knowledge of the risks of handling pesticides. His children were not to accompany him to the fields when he was spraying. He instructed them to wash his tomatoes thoroughly to remove the residues before eating. Yet, in his spraying demonstrations for his laborers, Lino did not wear protective gear. Soaked in the acrid smell and sticky residues, with knowledge of the potential harms of exposure, he exhibited a drive toward modernity, at whatever cost.

Taken together, these illustrations only begin to uncover how a focus only on harmful experiences of pesticides can miss sensory cues that speak to complex desires and competing concerns unfolding in African agriculture. We found (albeit in diverse and differently situated ways) that rural people are using pesticides in their embodied pursuits of future success, or even the mere ability to rest. We offer the "toxic sensorium" toward expanding literature on these and other situated experiences of living within spaces of toxic proliferation.

\section{Conclusion}

In the Global North, studies have examined consumer and farmer ambivalences over pesticides, acknowledging that people are unknowingly exposed to harmful contamination, and also that people regularly accept life with certain toxins. Pesticides enable the current system of large-scale industrialized agricultural production, even as the bodily risks of chemically saturated ecologies to both consumers and farmworkers are increasingly understood. Between 
the inadvertent ingestion of chemical residues and their active use and consumption, we see opportunities for scholarship to better consider the enduring structural violence facing many smallholders in Africa, alongside the ways that farmers may bring pesticides into their lives. Scholars of pesticides in SSA should not only treat toxicity in the negative sense of destruction and precarity, but explore the puzzles of desire, aspiration, and expectations of modernity, and how to proceed from those messy realities and contradictions (Ferguson 2006; Li 2014). New questions open up: How do farmers make pesticides "their own" technologies in knowledge and practices that potentially diverge from those in the Global North (Mavhunga 2018)? How do communities in Africa-internally diverse and sometimes divided-address questions of social justice related to chemical usage? In what ways do institutional attempts to monitor and regulate chemical use clash with smallholder farmers' projects of commercialization, modernity, and success? In what ways are development projects, governments, NGOs, and different types of farmers working at cross-purposes in terms of incentives and desires related to pesticide use?

While these questions would interest social scientists seeking to understand the complexities of African agrarian change, they are also important for informing the often stalled efforts by policymakers and others interested in reducing pesticide toxicities in SSA. Sarah Wiebe (2016, 2020) has argued for "sensing policy" that takes into account corporeal and visceral experiences and knowledges of everyday life. Complementing this, the "toxic sensorium" not only concerns the felt recognition of chemicals, but the messy dynamics of being aware of risks and desiring those chemicals anyway. This complex embrace of agrochemicals is often unattended to by scholars as well as policymakers. Policymakers who seek to "educate" farmers about safe use or promote agroecology could draw on these insights to better understand why (some) farmers embrace pesticides, and thereby also pay attention to heterogeneous lived experiences: differently situated people within a community do not perceive or experience the gains and risks of pesticide use equally.

The Anthropocene literature has been embattled over the problematic attribution of anthropogenic planetary destruction to an undifferentiated "we" of humanity (Hecht 2018). Living in an irreparably polluted world and in porous bodies means that nobody escapes chemical contamination (Agard-Jones 2016; Murphy 2017), and yet toxicity is unevenly distributed along lines of race, class, gender, and geographical region. In many respects, agrochemicals are a quintessential subject for unpacking the global inequalities underlying the Anthropocene: they are repurposed tools of imperialism that proliferated through African colonial encounters and violent market expansions; they represent the Global North knowingly polluting the Global South as its receptacle of waste for unrestricted capitalist accumulation; and they endure as neoliberal restructuring undermines the scientific resources needed to bring toxic contamination to light.

Amid this recognition of globally uneven responsibility, it is perhaps a simple argumentbut a critical one-that Africans should be given the same complexity of subjectivity permitted to Global North subjects. In our long-term research, we have witnessed peoples' complicated desires, including their concerns about the health and safety of their families and communities as well as their local environments, which coexist with the seeming imperative to live with chemicals in a growing embrace. Perhaps what is needed in this moment of Anthropocene debates, as Anna Tsing and colleagues (2017) among others have noted, is rich empiricisms, stories of the competing demands that humans navigate, and, crucially, not reducing lives solely to casualty or accomplice. In our case, this requires representation of African farmers beyond peasant essentialism and toward the multifarious contradictions of economic desires, bodily exposure, and social (in)visibility. The toxic sensorium becomes a method and an agenda of preoccupations toward that end. 


\section{ACKNOWLEDGMENTS}

We would like to thank the anonymous reviewers for their comments. Serena would like to acknowledge the generosity of many Mozambican farmers participating in her research. Jessie would like to thank the many people in Burkina Faso who assisted with her research, especially Drs. Abdoulaye Sanogo and Gabin Korbeogo, as well as participants at the 2019 Pesticide Politics in Africa Conference.

SERENA STEIN is a Researcher at Wageningen University in The Netherlands. As an anthropologist, her research investigates agrarian change, development politics, and environmental values on commodity frontiers in Mozambique, Brazil, and the United States. Her work also examines extractive linkages across the Global South and farming technologies amid climate change. Research for this article was funded by the Wenner Gren Foundation, National Science Foundation, Fulbright Foundation, and Princeton University. Email: serena.stein@wur.nl

JESSIE LUNA is an Assistant Professor of Sociology at Colorado State University. Her research focuses on cultural and embodied dimensions of how people make sense of and justify inequalities associated with neoliberal capitalism. She has conducted ethnographic fieldwork in southwestern Burkina Faso, focused on cotton farmers, and studied runners in Boulder, Colorado. Research for this article was supported by the American Association of University Women, the Fulbright Foundation, the National Science Foundation, and the University of Colorado Boulder. Email: jessie.luna@colostate.edu

\section{NOTES}

1. We recognize practical reasons for considering shared (though nonetheless heterogeneous and highly uneven) experiences across SSA. This is consistent with recent efforts by some researchers, farmers, and activists to address what are perceived to be common struggles across the continent, as demonstrated by the 2019 conference in Tanzania entitled "Pesticide Politics in Africa."

2. We use the term "smallholders" broadly to refer to those operating ten hectares or less, and typically without mechanization (De Bon et al. 2014; Sheahan and Barrett 2017; Williamson et al. 2008).

3. https://www.croplifeafrica.org/information-resources/videos-and-publications.

4. New plantations were often situated in the ruins of abandoned plantation projects that came before, from colonial operations of sisal and tea to recent short-lived experiments with biofuel production (Stein 2020).

5. "Highly toxic pesticides" or "highly hazardous pesticides" are chemicals classified as such by international health and agriculture agencies (FAO 2021) for causing severe or irreversible harm to human health and the environment.

\section{REFERENCES}

Aidoo, Atta Kwesi, Stephen Arthur, Grace Bolfrey-Arku, and Moses Brandford Mochiah. 2019. "Pesticides Abuse and Health Implications in Ghana: A Review." International Journal of Environment, Agriculture and Biotechnology 4 (3): 874-883. doi:10.22161/ijeab/4.3.39. 
Agard-Jones, Vanessa. 2016. “Chemical Kin/Esthesia." (Paper presented at the Annual Meeting of the American Anthropological Association, Minneapolis, 18 November).

Ajayi, Oluyede Clifford, Festus K. Akinnifesi, Gudeta Sileshi, and Adeola O. Ajayi. 2009. "Agricultural Policies and the Emergence of Cotton as the Dominant Crop in Northern Côte d'Ivoire: Historical Overview and Current Outlook." Natural Resources Forum 33 (2): 111-122. doi:10.1111/j.1477-8947 .2009.01215.x.

Andersson, Elina, and Ellinor Isgren. 2021. "Gambling in the Garden: Pesticide Use and Risk Exposure in Ugandan Smallholder Farming." Journal of Rural Studies 82: 76-86. doi:10.1016/j.jrurstud.2021 .01 .013 .

Andrade-Rivas, Federico, and Hanna-Andrea Rother. 2015. "Chemical Exposure Reduction: Factors Impacting on South African Herbicide Sprayers' Personal Protective Equipment Compliance and High Risk Work Practices." Environmental Research 142: 34-45. doi:10.1016/j.envres.2015.05.028.

Bababunmi, Enitan A. 1978. "Toxins and Carcinogens in the Environment: An Observation in the Tropics." Journal of Toxicology and Environmental Health 4 (5-6): 691-699. doi:10.1080/15287397 809529691.

Balayannis, Angeliki. 2019. "Routine Exposures: Reimaging the Visual Politics of Hazardous Sites." GeoHumanities 5 (2): 572-590. doi:10.1080/2373566X.2019.1624189.

Bayili, Bazoma, Richard Ouedraogo, Sylvain Ilboudo, Lamine Pooda, Macaire Bonkoungou, ..., and Jean Fidèle Bationo. 2019. "Characterization of Pesticides and Practices of Cotton Producers and Pesticides Sellers in the Cotton Zone of Bala’s Hippopotamus Pond Biosphere of Burkina Faso." Journal of Experimental Biology and Agricultural Sciences 7 (6): 554-568. doi:10.18006/2019.7(6) .554 .568 .

Biehl, João. 2007. Will to Live: Aids Therapies and Politics of Survival. Princeton: Princeton University Press.

Biehl, João and Adriana Petryna, eds. 2013. When People Come First: Critical Studies in Global Health. Princeton: Princeton University Press.

Boudia, Soraya, Angela N. H. Creager, Scott Frickel, Emmanuel Henry, Nathalie Jas, ..., and Jody Roberts. 2018. "Residues: Rethinking Chemical Environments." Engaging Science, Technology, and Society 4: 165-178. doi:10.17351/ests2018.245.

Bowen, Merle. 2000. The State against the Peasantry: Rural Struggles in Colonial and Postcolonial Mozambique. Charlottesville: University Press of Virginia.

Bräutigam, Deborah. 2009. The Dragon's Gift: The Real Story of China in Africa. Oxford: Oxford University Press.

Brown, Phil. 2007. Toxic Exposures: Contested Illnesses and the Environmental Health Movement. New York: Columbia University Press.

Büscher, Bram, and Robert Fletcher. 2020. Convivial Conservation: A Post-Capitalist Manifesto. London: Verso Books.

Chandler, M. T. 1976. "Reducing Pesticide Hazards to Honey Bees in Tropical East Africa." PANS 22: 35-42. doi:10.1080/09670877609411453.

Chen, Mel. 2011. "Toxic Animacies, Inanimate Affections." Journal of Lesbian and Gay Studies 17 (2-3): 265-286. doi:10.1215/10642684-1163400.

Clapp, Jennifer. 1994. "Africa, NGOs, and the International Toxic Waste Trade." Journal of Environment and Development 3 (2): 17-46. https://www.jstor.org/stable/44318044.

D’Alessandro, Cristina, and Leo Zulu. 2017. "From the Millennium Development Goals to the Sustainable Development Goals: Africa in the Post-2015 Development Agenda. A Geographical Perspective." African Geographical Review 36 (1): 1-18. doi:10.1080/19376812.2016.1253490.

Dalvie, Aqiel, Algernon Africa, and Leslie London. 2006. "Disposal of Unwanted Pesticides in Stellenbosch, South Africa." Science of the Total Environment 361 (1-3): 8-17. doi:10.1016/j.scitotenv .2005.09.049.

De Bon, Hubert, Joel Huat, Laurent Parrot, Antonio Sinzogan, Thibaud Martin, Eric Malezieux, and Jean-Francois Vayssieres. 2014. "Pesticide Risks from Fruit and Vegetable Pest Management by 
Small Farmers in Sub-Saharan Africa: A Review." Agronomy for Sustainable Development 34 (4): 723-736. doi:10.1007/s13593-014-0216-7.

Doro, Elijah, and Sandra Swart. 2019. "A Silenced Spring? Exploring Africa's 'Rachel Carson Moment': A Socioenvironmental History of the Pesticides in Tobacco Production in Southern Rhodesia, 194580." International Review of Environmental History 5 (2): 5-39. http://hdl.handle.net/1885/202889.

Dowd-Uribe, Brian. 2014. "Liberalisation Failed: Understanding Persistent State Power in the Burkinabè Cotton Sector from 1990 to 2004." Development Policy Review 32 (5): 545-566. doi:10.1111/dpr .12072 .

Etzel, R. A., D. N. Forthal, R. H. Hill, Jr., and A. Demby. 1986. "Fatal Parathion Poisoning in Sierra Leone." Bulletin of the World Health Organization 65 (5): 645-649. https://pubmed.ncbi.nlm.nih .gov/3501344/.

Fairet, Emilie, Sandra Bell, Kharl Remanda, and Joanna M. Setchell. 2014. "Rural Emptiness and Its Influence on Subsistence Farming in Contemporary Gabon." Society, Biology and Human Affairs 78 (1-2): 39-59. https://dro.dur.ac.uk/16214/.

FAO (Food and Agriculture Organization). 1999. Prevention and Disposal of Obsolete and Unwanted Pesticide Stocks in Africa and the Near East. Report from the Fourth Consultation Meeting. Food and Agriculture Organization of the United Nations, Rome, 24-25 May. http://www.fao.org/3/W8419E/ W8419e00.htm.

FAO (Food and Agriculture Organization). 2021. "Mozambique Prohibits Highly Hazardous Pesticides." http://www.fao.org/in-action/mozambique-prohibits-highly-hazardous-pesticides/en/ (accessed 26 March 2021).

Ferguson, James. 2006. Global Shadows: Africa in the Neoliberal World Order. Durham, NC: Duke University Press.

Ferrer, A. and R. Cabral. 1991. “Toxic Epidemics Caused by Alimentary Exposure to Pesticides: A Review." Food Additives and Contaminants 8 (6): 755-775. doi:10.1080/02652039109374034.

Flachs, Andrew. 2019. Cultivating Knowledge: Biotechnology, Sustainability, and the Human Cost of Cotton Capitalism in India. Tucson: University of Arizona Press.

Ford, Andrea. 2019. "Introduction: Embodied Ecologies." Society for Cultural Anthropology, 25 April. https://culanth.org/fieldsights/introduction-embodied-ecologies.

Forget, Gilles. 1989. Pesticides: Necessary but Dangerous Poisons. IDRC Report, July. https://inspectape dia.com/hazmat/Pesticides-Necessary-Dangerous-Poisons-Forget-1989.pdf.

Fouilleux, Eve, Nicolas Bricas, and Arlène Alpha. 2017. "Feeding 9 Billion People: Global Food Security Debates and the Productionist Trap." Journal of European Public Policy 24 (11): 1658-1677. doi:10 $.1080 / 13501763.2017 .1334084$.

Galt, Ryan E. 2013. "From Homo Economicus to Complex Subjectivities: Reconceptualizing Farmers as Pesticide Users." Antipode 45 (2): 336-356. doi:10.1111/j.1467-8330.2012.01000.x.

Garrigou, Alain, Catherine Laurent, Aurélie Berthet, Claudio Colosio, Nathalie Jas, Véronique DaubasLetourneux, ..., and J.-M. Jackson Filho. 2020. "Critical Review of the Role of PPE in the Prevention of Risks Related to Agricultural Pesticide Use.” Safety Science 123: 104527. doi:10.1016/j.ssci .2021.105191.

Gesesew, Hailay Abrha, Kifle Woldemichael, Desalegn Massa, and Lillian Mwanri. 2016. "Farmers Knowledge, Attitudes, Practices and Health Problems Associated with Pesticide Use in Rural Irrigation Villages, Southwest Ethiopia.” PloS One 11 (9): e0162527. doi:10.1371/journal.pone.0162527.

Haggblade, Steven, Melinda Smale, Veronique Thériault, and Amidou Assima. 2017. "Causes and Consequences of Increasing Herbicide Use in Mali." European Journal of Development Research 29 (3): 648-674. doi:10.1057/s41287-017-0087-2.

Hambleton, Edson J. 1955. "Factors Influencing the Demand for Pesticides in Tropical Agriculture." In Pesticides in Tropical Agriculture, 9-13. Washington, DC: American Chemical Society.

Hardin, Sarah. 2020. "Charging Responsibility for the Repercussions of Pesticide Usage in Post War Francophone Africa." Environment and History 27 (1): 37-63. doi:10.3197/096734019X154634 32086973. 
Hecht, Gabrielle. 2018. “The African Anthropocene.” Aeon, 6 February. https://aeon.co/essays/if-wetalk-about-hurting-our-planet-who-exactly-is-the-we.

Hockey, John, and Jacquelyn Allen-Collinson. 2009. “The Sensorium at Work: The Sensory Phenomenology of the Working Body." The Sociological Review 57 (2): 217-239. doi:10.1111/j.1467-954X .2009.01827.x.

Hunsmann, Moritz. 2016. "Pushing 'Global Health' out of Its Comfort Zone: Lessons from the Depoliticization of AIDS Control in Africa." Development and Change 47 (4): 798-817. doi:10.1111/ dech.12241.

Ingram, W. R., and J. C. Davies. 1965. "Recent Advances in Pest Control on Cotton in Uganda." East African Agricultural and Forestry Journal 31: 169-174. doi:10.1080/00128325.1965.11662036.

Kay, Kingsley. 1950. "Health Problems of the New Organic Insecticides." Canadian Journal of Public Health 41 (9): 374-380. https://www.jstor.org/stable/41980231.

Kütting, Gabriela. 2003. "Globalization, Poverty and the Environment in West Africa: Too Poor to Pollute?” Global Environmental Politics 3 (4): 42-60. doi:10.1162/152638003322757925.

Lekei, Elikana E., Aiwerasia V. Ngowi, and Leslie London. 2014. "Farmers' Knowledge, Practices and Injuries Associated with Pesticide Exposure in Rural Farming Villages in Tanzania." BMC Public Health 14 (1): 389. doi:10.1186/1471-2458-14-389.

Lekei, Elikana E., Aiwerasia V. Ngowi, and Leslie London. 2016. "Underreporting of Acute Pesticide Poisoning in Tanzania: Modelling Results from Two Cross-Sectional Studies." Environmental Health 15 (1): 118. doi:10.1186/s12940-016-0203-3.

Lekei, Elikana E., Aiwerasia V. Ngowi, Habib Mkalanga, and Leslie London. 2017. "Knowledge and Practices Relating to Acute Pesticide Poisoning among Health Care Providers in Selected Regions of Tanzania." Environmental Health Insights 11. doi:10.1177/1178630217691268.

Li, Tania Murray. 2014. Land's End: Capitalist Relations on an Indigenous Frontier. Durham, NC: Duke University Press.

Little, Peter C. 2019. "Bodies, Toxins, and E-Waste Labour Interventions in Ghana: Toward a Toxic Postcolonial Corporality?” Revista de Antropología Iberoamericana 14 (1): 51-71. https://www.aibr.org/ antropologia/netesp/numeros/1401/140104e.pdf.

Lipman, Zada. 2002. “A Dirty Dilemma: The Hazardous Waste Trade." Harvard International Review 23 (4): 67-71. https://sites.oxy.edu/whitney/xaccess/csp2004/envt_hir_2002.htm.

Livingston, Julie. 2012. "Neoplastic Africa: Mapping Circuits of Toxicity and Knowledge." In Improvising Medicine: An African Oncology Ward in an Emerging Cancer Epidemic, 29-51. Durham, NC: Duke University Press.

London, Leslie. 2003. "Human Rights, Environmental Justice, and the Health of Farm Workers in South Africa." International Journal of Occupational and Environmental Health 9 (1): 59-68. doi:10.1179/ 107735203800328876.

London, Leslie, Sylvie De Grosbois, Catharina Wesseling, Sophia Kisting, Hanna Andrea Rother, and Donna Mergler. 2002. "Pesticide Usage and Health Consequences for Women in Developing Countries: Out of Sight out of Mind?" International Journal of Occupational and Environmental Health 8 (1): 46-59. doi:10.1179/oeh.2002.8.1.46.

Luna, Jessie K. 2018. “'Getting out of the Dirt': Racialized Modernity and Environmental Inequality in the Cotton Sector of Burkina Faso." Environmental Sociology 4 (2): 221-234. doi:10.1080/23251042 .2017.1396657.

Luna, Jessie K. 2019. “The Ease of Hard Work: Embodied Neoliberalism among Rocky Mountain Fun Runners." Qualitative Sociology 42: 251-271. doi:10.1007/s11133-019-9412-8.

Luna, Jessie K. 2020. “Pesticides Are Our Children Now': Cultural Change and the Technological Treadmill in the Burkina Faso Cotton Sector." Agriculture and Human Values 37 (2): 449-462. doi:10 .1007/s10460-019-09999-y.

Luna, Jessie K., and Brian Dowd-Uribe. 2020. "Knowledge Politics and the Bt Cotton Success Narrative in Burkina Faso." World Development 136. doi:10.1016/j.worlddev.2020.105127.

MacKendrick, Norah. 2018. Better Safe than Sorry: How Consumers Navigate Exposure to Everyday Toxics. Oakland: University of California Press. 
Mavhunga, Clapperton. 2018. The Mobile Workshop: The Tsetse Fly and African Knowledge Production. Cambridge, MA: MIT Press.

McGoey, Linsey. 2019. The Unknowers: How Strategic Ignorance Rules the World. London: Zed Books.

Melo, Antonio da Piedade, Isaura Zandamela, Marcio Sitoe, Celia Melo, and Nelio Candido. 2019. "The Use of Pesticides in Tomato Production: Exposition of Chokwe Farmers-Mozambique." International Journal of Research in Agricultural Sciences 6 (6): 183-192. https://ijras.com/administrator/ components/com_jresearch/files/publications/IJRAS_800_FINAL.pdf.

Mengistie, Belay T., Arthur P. J. Mol, Peter Oosterveer, and Belay Simane. 2015. "Information, Motivation and Resources: The Missing Elements in Agricultural Pesticide Policy Implementation in Ethiopia." International Journal of Agricultural Sustainability 13 (3): 240-256. doi:10.1080/14735903 .2014.959330.

Mojola, Sanyu A. 2014. Love, Money, and HIV: Becoming a Modern African Woman in the Age of AIDS. Oakland: University of California Press.

Moran, V. Cliff, John Hoffmann, and Helmuth Zimmermann. 2013. "100 Years of Biological Control of Invasive Alien Plants in South Africa: History, Practice and Achievements." South African Journal of Science 109 (9): 1-6. doi:10.1590/SAJS.2013/A0022.

Moseley, William G., Matthew A. Schnurr, and Rachel Bezner Kerr. 2017. Africa's Green Revolution: Critical Perspectives on New Agricultural Technologies and Systems. New York: Routledge.

Mrema, Ezra Jonathan, Aiwerasia Vera Ngowi, Stephen Simon Kishinhi, and Simon Henry Mamuya. 2017. "Pesticide Exposure and Health Problems among Female Horticulture Workers in Tanzania." Environmental Health Insights 11: 1-13. doi:10.1177/1178630217715237.

Muleme, James, Clovice Kankya, John C. Ssempebwa, Stella Mazeri, and Adrian Muwonge. 2017. “A Framework for Integrating Qualitative and Quantitative Data in Knowledge, Attitude, and Practice Studies: A Case Study of Pesticide Usage in Eastern Uganda." Frontiers in Public Health 5: 318. doi:10.3389/fpubh.2017.00318.

Murphy, Michelle. 2017. "Alterlife and Decolonial Chemical Relations." Cultural Anthropology 32 (4): 494-503. https://www.semanticscholar.org/paper/ALTERLIFE-AND-DECOLONIAL-CHEMICALRELATIONS-Murphy/68426e107f3815c98f8e8cdab657a09a44be9417.

Murray, Douglas L., and Peter Leigh Taylor. 2000. “Claim No Easy Victories: Evaluating the Pesticide Industry’s Global Safe Use Campaign.” World Development 28 (10): 1735-1749. doi:10.1016/ S0305-750X(00)00059-0.

Nading, Alex M. 2020. "Living in a Toxic World." Annual Review of Anthropology 49 (1): 209-224. doi:10.1146/annurev-anthro-010220-074557.

Naidoo, Saloshni, Leslie London, Alex Burdorf, Rajen N. Naidoo, and Hans Kromhout. 2008. "Agricultural Activities, Pesticide Use and Occupational Hazards among Women Working in Small Scale Farming in Northern KwaZulu-Natal, South Africa." International Journal of Occupational and Environmental Health 14 (3): 218-224. doi:10.1179/oeh.2008.14.3.218.

Negatu, Beyene, Hans Kromhout, Yalemtshay Mekonnen, and Roel Vermeulen. 2016. "Use of Chemical Pesticides in Ethiopia: A Cross-Sectional Comparative Study on Knowledge, Attitude and Practice of Farmers and Farm Workers in Three Farming Systems." Annals of Occupational Hygiene 60 (5): 551-566. doi:10.1093/annhyg/mew004.

Ngowi, Aiwerasia V., Ezra Mrema, and Stephen Kishinhi. 2016. "Pesticide Health and Safety Challenges Facing Informal Sector Workers: A Case of Small-Scale Agricultural Workers in Tanzania." New Solutions: A Journal of Environmental and Occupational Health Policy 26 (2): 220-240. doi:10.1177/ 1048291116650262.

Nixon, Robert. 2011. Slow Violence and the Environmentalism of the Poor. Cambridge, MA: Harvard University Press.

Nyantakyi-Frimpong, Hanson, Godwin Arku, and Daniel Kweku Baah Inkoom. 2016. "Urban Agriculture and Political Ecology of Health in Municipal Ashaiman, Ghana." Geoforum 72: 38-48. doi:10.1016/j.geoforum.2016.04.001.

Oreskes, Naomi, and Erik M. Conway. 2011. Merchants of Doubt: How a Handful of Scientists Obscured the Truth on Issues from Tobacco Smoke to Global Warming. New York: Bloomsbury. 
Parkhurst, Justin O., and Moritz Hunsmann. 2015. "Breaking out of Silos: The Need for Critical Paradigm Reflection in HIV Prevention." Review of African Political Economy 42 (145): 477-487. doi:10 $.1080 / 03056244.2015 .1064373$.

Patel, Raj. 2013. “The Long Green Revolution." Journal of Peasant Studies (40) 1: 1-63. doi:10.1080/0306 6150.2012.719224.

Roberts, Elizabeth F. S. 2017. "What Gets inside: Violent Entanglements and Toxic Boundaries in Mexico City." Cultural Anthropology 32 (4): 592-619. doi:10.14506/ca32.4.07.

Rother, Hanna-Andrea. 2010. "Falling through the Regulatory Cracks: Street Selling of Pesticides and Poisoning among Urban Youth in South Africa." International Journal of Occupational and Environmental Health 16 (2): 183-194. doi:10.1179/107735210799160336.

Rother, Hanna-Andrea. 2016. "Pesticide Vendors in the Informal Sector: Trading Health for Income." NEW SOLUTIONS: A Journal of Environmental and Occupational Health Policy 26 (2): 241-252. doi:10.1177/1048291116651750.

Rother, Hanna-Andrea. 2018. “Pesticide Labels: Protecting Liability or Health? Unpacking 'Misuse' of Pesticides." Current Opinion in Environmental Science \& Health 4: 10-15. doi:10.1016/j.coesh.2018 .02 .004 .

Rother, Hanna-Andrea, Ruth Hall, and Leslie London. 2008. "Pesticide Use among Emerging Farmers in South Africa: Contributing Factors and Stakeholder Perspectives." Development Southern Africa 25 (4): 399-424.doi:10.1080/03768350802318464.

Sankoh, Alhaji I., Rebecca Whittle, Kirk T. Semple, Kevin C. Jones, and Andrew J. Sweetman. 2016. “An Assessment of the Impacts of Pesticide Use on the Environment and Health of Rice Farmers in Sierra Leone." Environment International 94: 458-466. doi:10.1016/j.envint.2016.05.034.

Schnurr, Matthew. 2019. Africa's Gene Revolution: Genetically Modified Crops and the Future of African Agriculture. Montreal: McGill-Queen's University Press.

Shapiro, Nicholas. 2015. "Attuning to the Chemosphere: Domestic Formaldehyde, Bodily Reasoning, and the Chemical Sublime." Cultural Anthropology 30 (3): 368-393. doi:10.14506/ca30.3.02.

Shattuck, Annie. 2020. "Toxic Uncertainties and Epistemic Emergence: Understanding Pesticides and Health in Lao PDR.” Annals of the American Association of Geographers 111 (1): 216-230. doi:10 $.1080 / 24694452.2020 .1761285$.

Shattuck, Annie. 2021a. "Generic, Growing, Green? The Changing Political Economy of the Global Pesticide Complex.” Journal of Peasant Studies 48 (2): 231-253. doi:10.1080/03066150.2020.1839053.

Shattuck, Annie. 2021b. "Risky Subjects: Embodiment and Partial Knowledges in the Safe Use of Pesticide.” Geoforum 123: 153-161. doi:10.1016/j.geoforum.2019.04.029.

Sheahan, Megan, and Christopher B. Barrett. 2017. "Ten Striking Facts about Agricultural Input Use in Sub-Saharan Africa." Food Policy 67: 12-25. doi:10.1016/j.foodpol.2016.09.010.

Sheahan, Megan, Christopher B. Barrett, and Casey Goldvale. 2017. "Human Health and Pesticide Use in Sub-Saharan Africa." Agricultural Economics 48 (S1): 27-41. doi:10.1111/agec.12384.

Shilomboleni, Helena. 2018. "African Green Revolution, Food Sovereignty and Constrained Livelihood Choice in Mozambique." Canadian Journal of African Studies 52 (2): 115-137. doi:10.1080/00083 968.2018.1483833.

Shilomboleni, Helena. 2020. "Political Economy Challenges for Climate Smart Agriculture in Africa." Agriculture and Human Values 37: 1195-1206. doi:10.1007/s10460-020-10126-5.

Sitoe, Marcio, Gabriel Sidónio Moiane, and Célia Cristina Sitoe. 2017. "Exposure to Agriculture Pesticides by Farmers of Chaimite Administrative Post.” Revista de Ciências Agroveterinárias 16 (4): $180-186$.

Snyder, Jason, Jennifer Smart, Joey Goeb, and David Tschirley. 2018. "Pesticide use in Sub-Saharan Africa: Estimates, Projections, and Implications in the Context of Food System Transformation" (Paper presented at the 2018 Agricultural and Applied Economics Association Annual Meeting, Washington, DC, United States, 5-7 August). https://ageconsearch.umn.edu/record/27390.

Sorensen, J. P. R., D. J. Lapworth, D. C. W. Nkhuwa, M. E. Stuart, D. C. Gooddy, . . and R. A. Bell. 2015. "Emerging Contaminants in Urban Groundwater Sources in Africa." Water Research 72: 51-63. doi:10.1016/j.watres.2014.08.002. 
Spackman, Christy, and Gary Burlingame. 2018. "Sensory Politics: The Tug-of-War between Potability and Palatability in Municipal Water Production." Social Studies of Science 48: 350-371. doi:10 $.1177 / 0306312718778358$.

Stadlinger, Nadja, Aviti J. Mmochi, Sonja Dobo, Emma Gyllbäck, and Linda Kumblad. 2011. "Pesticide Use among Smallholder Rice Farmers in Tanzania." Environment, Development and Sustainability 13 (3): 641-656. doi:10.1007/s10668-010-9281-5.

Stein, Serena. 2020. "Witchweed: A Parasitic Plant Devastates Peasant Crops on Abandoned Plantations in Southern Africa." In The Feral Atlas, ed. Anna Tsing, Jennifer Deger, Alder Saxena Keleman, and Feifei Zhou. Redwood City, CA: Stanford University Press.

Stein, Serena. 2021. "Kindred Frontiers: South-South Experiments in Aid, Agriculture, and Accumulation in Mozambique." PhD diss., Princeton University.

Stein, Serena, and Marc Kalina. 2019. "Becoming an Agricultural Growth Corridor: African Megaprojects at a Situated Scale." Environment and Society: Advances in Research 10: 83-100. doi: 10.3167/ ares.2019.100106.

Stillwaggon, Eileen. 2006. AIDS and the Ecology of Poverty. New York: Oxford University Press.

Stoler, Ann. 2016. Duress: Imperial Durabilities in Our Times. Durham, NC: Duke University Press.

Tijani, A. A. 2006. "Pesticide Use Practices and Safety Issues: The Case of Cocoa Farmers in Ondo State, Nigeria." Journal of Human Ecology 19 (3): 183-190. doi:10.1080/09709274.2006.11905876.

Tousignant, Noémi. 2018. Edges of Exposure: Toxicology and the Problem of Capacity in Postcolonial Senegal. Durham, NC: Duke University Press.

Tsing, Anna, Heather Swanson, Elaine Gan, and Nils Bubandt, eds. 2017. Arts of Living on a Damaged Planet: Ghosts and Monsters of the Anthropocene. Minneapolis: University of Minnesota Press.

Valdivia, Gabriela. 2018. "Wagering Life' in the Petro-City: Embodied Ecologies of Oil Flow, Capitalism, and Justice in Esmeraldas, Ecuador." Annals of the American Association of Geographers 108 (2): 549-557. doi:10.1080/24694452.2017.1369389.

World Health Organization. 1956. "Toxic Hazards of Pesticides to Man: Report of a Study Group." Geneva: World Health Organization.

Wiebe, Sarah Marie. 2016. Everyday Exposure: Indigenous Mobilization and Environmental Justice in Canada's Chemical Valley. Vancouver: University of British Columbia Press.

Wiebe, Sarah Marie. 2020. "Sensing Policy: Engaging Affected Communities at the Intersections of Environmental Justice and Decolonial Futures." Politics, Groups, and Identities 8 (1): 181-193. doi:10.1080/21565503.2019.1629315.

Wier, David, and Mark Schapiro. 1981. Circle of Poison: Pesticides and People in a Hungry World. Oakland: Institute for Food and Development Policy.

Wiese, I. H., and J. Bot. 1971. "Pesticide Regulation in South Africa." In Residue Reviews, ed. Francis A. Gunther, 49-63. New York: Springer.

Williamson, Stephanie, Andrew Ball, and Jules Pretty. 2008. "Trends in Pesticide Use and Drivers for Safer Pest Management in Four African Countries." Crop Protection 27 (10): 1327-1334. doi:10.1016/j.cropro.2008.04.006.

Zinyama, Lovemore. 1992. "Technology Adoption and Post-Independence Transformation of the Small-Scale Farming Sector in Zimbabwe." In Urban and Regional Change in Southern Africa, ed. David W. Smith, 180-202. London: Routledge. 